\title{
MENTAL SUFFERING.
}

A case of an unusual character came before the Leicester borough magistrates lately, when a commercial traveller was charged with causing mental suffering to his four children by threatening and neglecting them. The prosecution was instituted by the Society for Preventing Cruelty to Children. The evidence showed that the defendant for three months had done no work, and had been almost continuously intoxicated. He threatened his children with violence, and the medical evidence showed that the children had suffered in their nervous system through fear on account of the threats of violence; but the defendant had never actually struck them, as they were protected by his wife. The Bench sentenced him to three months' imprisonment with hard labour.

We quote this as corroborative of Dr. Macdonald's position in regard to alcoholism as a cause of insanity, as reported in this number of the JourNAl. In this case a drunkard subjects his family to privations and incalculable mental stress. We congratulate the Society for Preventing Cruelty to Children on their activity in the matter.

\section{L'INTERMEDIARE DES NEUROLOGISTES ET DES ALIENISTES}

We are favoured with the prospectus of a new journal which is to be printed in French, English, and German. It is designed to be a medium for the exchange of ideas on subjects connected with our department, principally in the form of notes and queries. The questions and answers are to be classed under the headings Neurology, Psychiatry, and Psycho-physiology. The most recent discoveries and theories will be recorded with references to original articles, and summaries of current knowledge will be published from time to time. The various congresses and meetings of learned societies in connection with these matters will be duly noticed in detail. We heartily commend this new departure, and hope that it will be widely supported by our readers. The subscription is only $7 \mathrm{fr}$. 50 per annum for the monthly issue, which will be published by Félix Alcan, 108, Boulevard Saint-Germain, Paris.

\section{CORRESPONDENCE.}

From Dr. J. Sanderson Christison.

The last issue of your esteemed JourNal contains what purports to be a "review" of my brochure, Crime and Criminals, and which contains such a sweeping condemnation and gross misrepresentation of my little book, that in justice both to myself and the readers of the JourNAL I ask permission for a brief reply.

The "reviewer" first observes that it " is not a scientific work," while he in no way indicates that it is not, although he quotes two or three fragments of sentences which probably do not correspond with his views. He fails to observe what is stated in the preface, that the book was written for the general reader, and consequently the subject-matter is presented in a form and manner calculated to interest the public. He also says that it "is conceived in execrable American-English, and teems with slang words redolent of the Bowery ;" but he fails to mention that the slang terms are quotations from the prisoners, and given as such to better indicate their meanings, which are often much easier understood than defined.

The "reviewer" flatly denies the truth of my statement that "crimes are now nearly five times as numerous as forty years ago," but he omits to say that I base the statement upon the official statistics of the United States, and thus refer to America only. I am aware that English statistics show a decrease of crime in late years. In America the ratio of incarcerated criminals to the general population was-for 1850,1 to 3442 ; 1860 , I to $1 \cdot 647 ; 1870$, I to $1 \cdot 171 ; 1880,1$ to 850 ; I890, I to 757 . 
Dr. Paul Bartholow, of Philadelphia, has shown (Journ. Amer. Medical Association, November 14th, 1896) that homicides in the United States were nearly six times more in 1895 than in 1885 . The foregoing are facts the public of America must attend to and intelligently deal with. The "reviewer" declares the book is "unnecessary," yet society and its machinery are chiefly responsible for the crime within it, and I know of no other book which presents typical cases of every-day offenders described in a way conducive to a better understanding by the public of the main factors in our criminal problem. And surely no one author can expect to reach the whole reading public. Medical psychologists do not make our laws.

So far, at the hands of " reviewers" my book has met with only commendation or tirade, and surely tirade is not criticism, nor even review. Let reviewers observe the golden rule, and be at least fair and honest. They have the facts before them, if they do not always have the requisite understanding.

[I have been favoured with the perusal of the above letter anent my review of Dr. Christison's book, Crime and Criminals, in the last number of the Journal. Dr. Christison first quarrels with me for saying that his book "is not a scientific work," and then proceeds to admit the justice of the statement ; ditto as regards the slang terms employed. As to the character of the English in which the text is conceived, a glance at the book itself will suffice to condone my use of the word "execrable." He next accuses me of "flatly denying" his statement that "crimes are nearly five times as numerous as forty years ago," whereas the words I used were "which we venture to doubt." As to the book being "unnecessary," that is only my opinion as reviewer. I must apologise to Dr. Christison for not having been able to take his book seriously, and for having treated it with a levity which he evidently considers undeserved. As I remain unable, after re-perusal of it, to modify my already expressed opinion, I must ask him to ascribe my want of appreciation to a lack of the "requisite understanding." - THE REVIEWER.]

\section{THE LUNACY COMMISSION.}

The retirement of Dr. Southey from the Lunacy Commission will be a source of regret to those members of our association who have had the best opportunity of knowing his worth, and the uniformly high ideas that he has maintained in the discharge of his duties. It is to be hoped that the onerous character of those duties, owing to the obvious and notorious understaffing of the Commission, has not had a share in leading to his retirement.

Dr. Sydney Coupland, who succeeds Dr. Southey, has a reputation both professional and individual that ensures his becoming a very successful member of the Commission. His long connection with the Middlesex Hospital has given him a very wide circle of friends, who regret the loss of his services to that institution, and who, we are informed, intend to express that regret in the practical form of a handsome testimonial.

\section{OBITUARY.}

JoHN BYWATER WARD.

John Bywater Ward, M.A., M.D.Cantab. Born March 18th, 1844; died October 3rd, 1898. Medical Superintendent and Secretary of the Warneford Asylum, Oxford.

Dr. Ward was a native of Leeds. He was the second son of Mr. William Sykes Ward, solicitor, of that city, and his wife Caroline, daughter of Mr. John Bywater, also of Leeds. In 1856 he entered the Leeds Grammar School, where he received the early part of his general education. On leaving the grammar school he became a student at the Leeds School of Medicine. He the entered at Caius College, Cambridge, as a Scholar, and graduated B.A. in 1867, taking a Second Class in Natural Science. He took the degree of M.B. in 1868, and became M.D. in 1872 . He also held the diplomas of M.R.C.S.Eng., and L.S.A. His education being finished, Dr. Ward became one of the house surgeons to the Sheffield Infirmary, a post which he appears to have held for about two years. He then accepted a clinical clerkship at the West Riding Asylum under 